\title{
SELECTIVE POST-TRAINING TIME WINDOW FOR MEMORY CONSOLIDATION INTERFERENCE OF CANNABIDIOL INTO THE PREFRONTAL CORTEX: REDUCED DOPAMINERGIC MODULATION AND IMMEDIATE GENE EXPRESSION IN LIMBIC CIRCUITS
}

\author{
MATHEUS TEIXEIRA ROSSIGNOLI, ${ }^{2}$ \\ CLEITON LOPES-AGUIAR, ${ }^{\mathrm{b}}$ RAFAEL NAIME \\ RUGGIERO, ${ }^{a}$ RAQUEL ARAUJO DO VAL DA SILVA, \\ LEZIO SOARES BUENO-JUNIOR, \\ LUDMYLA KANDRATAVICIUS, ${ }^{a}$ JOSÉ EDUARDO \\ PEIXOTO-SANTOS, ${ }^{a}$ JOSÉ ALEXANDRE CRIPPA, \\ JAIME EDUARDO CECILIO HALLAK, ${ }^{2}$ \\ ANTONIO WALDO ZUARDI, \\ RAPHAEL ESCORSIM SZAWKA, \\ JANETE ANSELMO-FRANCI, ${ }^{\mathrm{C}}$ JOÃO PEREIRA LEITE ${ }^{a}$ \\ AND RODRIGO NEVES ROMCY-PEREIRA ${ }^{d *}$ \\ ${ }^{a}$ Department of Neuroscience and Behavior Science, Ribeirão \\ Preto Medical School, University of São Paulo, Ribeirão Preto - SP, \\ Brazil \\ ${ }^{\mathrm{b}}$ Department of Physiology and Biophysics, Institute of \\ Biological Sciences, Federal University of Minas Gerais, \\ Belo Horizonte - MG, Brazil \\ c Department of Morphology, Physiology and Basic \\ Pathology, School of Dentistry of Ribeirão Preto, University of \\ São Paulo, Ribeirão Preto - SP, Brazil \\ ${ }^{\mathrm{d}}$ Brain Institute, Federal University of Rio Grande do Norte, Natal \\ - RN, Brazil
}

Abstract-The prefrontal cortex (PFC), amygdala and hippocampus display a coordinated activity during acquisition of associative fear memories. Evidence indicates that PFC

\footnotetext{
${ }^{*}$ Corresponding author.

E-mail addresses: rossignoli.mt@gmail.com (M. T. Rossignoli), cleitonbiousp@gmail.com (C. Lopes-Aguiar), rafaruggiero@gmail. com (R. N. Ruggiero), raqueldoval@ig.com.br (R. A. Do Val da Silva), lezioneuro@gmail.com (L. S. Bueno-Junior), ludykandra@ gmail.com (L. Kandratavicius), peixotosantos@yahoo.com.br (J. E. Peixoto-Santos), jcrippa@fmrp.usp.br (J. A. Crippa), jhallak@ fmrp.usp.br (J. E. Cecilio Hallak), awzuardi@fmrp.usp.br (A. W. Zuardi), reszawka@icb.ufmg.br (R. E. Szawka), jaafranc@ usp.br (J. Anselmo-Franci), jpleite@fmrp.usp.br (J. P. Leite), rnrpereira@neuro.ufrn.br (R. N. Romcy-Pereira).

Abbreviations: 5-HIAA, 5-hydroxyindole-3-acetic acid; AMPA, aminohydroxymethyl isoxazole propionate receptor; ANOVA, analysis of variance; BLA, basolateral nucleus of the amygdala; CA, Ammon's horn of the hippocampus; $\mathrm{CB}_{1}$, cannabinoid subtype 1 receptor; $\mathrm{CB}_{2}$, cannabinoid subtype 2 receptor; CBD, cannabidiol; DA, dopamine; DG, granular layer of the dentate gyrus; DOPAC, 3,4-dihydroxyphenylacetic acid; EDTA, ethylenediaminetetraacetic acid; $\mathrm{GABA}_{A}, \gamma$-aminobutyrate type A receptor; HPLCD-ED, high-performance liquid chromatography with electrochemical detection; MD, mediodorsal thalamic nucleus; mPFC, medial prefrontal cortex; NMDA, glutamate $\mathrm{N}$-methyl-D-aspartate receptor; PBS, phosphate-buffered saline; PFA, paraformaldehyde; $\mathrm{PFC}$, prefrontal cortex; $\mathrm{PL}$, prelimbic area of the prefrontal cortex; PVN, paraventricular thalamic nucleus; Re, reuniens thalamic nucleus; SEM, standard error of mean; TRPV1, vanilloid subtype 1 receptor; VEH, vehicle.
}

engagement in aversive memory formation does not progress linearly as previously thought. Instead, it seems to be recruited at specific time windows after memory acquisition, which has implications for the treatment of posttraumatic stress disorders. Cannabidiol (CBD), the major non-psychotomimetic phytocannabinoid of the Cannabis sativa plant, is known to modulate contextual fear memory acquisition in rodents. However, it is still not clear how CBD interferes with PFC-dependent processes during post-training memory consolidation. Here, we tested whether intra-PFC infusions of CBD immediately after or $5 \mathrm{~h}$ following contextual fear conditioning was able to interfere with memory consolidation. Neurochemical and cellular correlates of the CBD treatment were evaluated by the quantification of extracellular levels of dopamine (DA), serotonin, and their metabolites in the PFC and by measuring the cellular expression of activity-dependent transcription factors in cortical and limbic regions. Our results indicate that bilateral intra-PFC CBD infusion impaired contextual fear memory consolidation when applied $5 \mathrm{~h}$ after conditioning, but had no effect when applied immediately after it. This effect was associated with a reduction in DA turnover in the PFC following retrieval 5 days after training. We also observed that post-conditioning infusion of CBD reduced c-fos and zif-268 protein expression in the hippocampus, PFC, and thalamus. Our findings support that CBD interferes with contextual fear memory consolidation by reducing PFC influence on cortico-limbic circuits. (C) 2017 IBRO. Published by Elsevier Ltd. All rights reserved.

Key words: cannabidiol, contextual fear memory, medial prefrontal cortex, dopamine, C-fos.

\section{INTRODUCTION}

Long-term memory consolidation of emotional events is essential for the organism survival. Impairment of its mechanisms is thought to be associated with maladaptive retrieval of traumatic events present in some psychiatric conditions, such as post-traumatic stress disorder (Parsons and Ressler, 2013). The encoding of emotional events is known to require the coordination of activity in limbic, thalamic and prefrontal cortical (PFC) circuits (Tayler and Wiltgen, 2013; Tovote et al., 2015). It has been demonstrated that the consolidation of some forms of memories can be modulated at distinct post-training time-windows (Dudai et al., 2015). For 
instance, pharmacological manipulations of the PFC of rats at 3-6 $\mathrm{h}$ after conditioning are more effective in disrupting associative fear memory consolidation than treatments performed immediately after conditioning (Souza et al., 2000; Izquierdo et al., 2006, 2007; Gonzalez et al., 2014). A possible mechanism involves the synthesis of new proteins required for strengthening synaptic connections in fear-related circuits. In addition, microstructural changes (Sandkühler and Lee, 2013) and activity-dependent gene expression have particular time-courses during memory consolidation (Bero et al., 2014; Aceti et al., 2015). These findings suggest that post-learning "sensitive" periods are windows of opportunity during which traumatic memories can be manipulated.

Cannabidiol (CBD) is the major non-psychotomimetic phytocannabinoid component of the Cannabis sativa plant (Mechoulam and Hanuš, 2002). Despite its broad pharmacological action, CBD has been considered a potential therapeutic agent for treating some neurological and psychiatric disorders (Izzo et al., 2009; Devinsky et al., 2014) (Pertwee, 2008; Campos et al., 2012). CBD is known to act on multiple molecular targets and regulate dopaminergic and serotoninergic systems (MurilloRodríguez et al., 2011; Fogaça et al., 2014). In particular, it is known to regulate DA release in limbic structures and serotonin subtype $1 \mathrm{~A}$ receptor $\left(5-\mathrm{HT} 1_{\mathrm{A}}\right)$-mediated neurotransmission in PFC (Murillo-Rodríguez et al., 2011; Fogaça et al., 2014).

Behavioral pharmacology experiments have shown that $\mathrm{CBD}$ can modulate the acquisition and extinction of a contextual fear conditioning (Resstel et al., 2006; Bitencourt et al., 2008). Direct infusion of CBD into the PFC prior to conditioning is sufficient to disrupt associative fear memory in rats (Lemos et al., 2010; Do Monte et al., 2013). However, it remains to be elucidated whether CBD can influence PFC-dependent processing between the period of 3-6 h of consolidation phase. Here, we tested whether intra-PFC infusion of CBD immediately after or $5 \mathrm{~h}$ following contextual fear conditioning was able to interfere with the formation of an aversive memory. In order to explore the possible mechanisms associated with the intra-PFC CBD infusion, we also evaluated the extracellular levels of monoamines and their metabolites in the PFC and the cellular expression of activity-dependent proteins c-fos and zif-268 in relevant brain regions. We hypothesized that intra-PFC CBD infusion differentially impacts associative memory consolidation depending on the selected post-conditioning temporal window.

\section{EXPERIMENTAL PROCEDURES}

\section{Animals}

We used seventy-three adult male Wistar rats (250$400 \mathrm{~g}$ ) housed in standard rodent cages (2-3 rats/cage). Animals were maintained at $25 \pm 2{ }^{\circ} \mathrm{C}$ temperature and a 12-h light/dark cycle with lights on at 07:00 h. During all experiments, food and water were freely available. Each behavioral test was conducted during the light phase using independent experimental groups consisting of 9-19 rats per group. All procedures were performed according to the Brazilian College of Animal Experimentation (COBEA) guidelines for animal research, affiliated with the International Council for Laboratory Animal Science (ICLAS). Experiments were approved by the Ethics Commission at the University of São Paulo and performed to minimize animal suffering.

\section{Stereotaxic surgery}

Rats were anesthetized with ketamine $(100 \mathrm{mg} / \mathrm{kg}$ i.p.) and xylazine $(15 \mathrm{mg} / \mathrm{kg}$ i.p.) and head-fixed in a stereotaxic frame (Insight, Brazil). Body temperature was maintained at $37 \pm 0.5^{\circ} \mathrm{C}$ by using a heating pad, and the level of anesthesia was verified by the tail pinch reflex. In brief, the skull was exposed, cleaned and two stainless steel guide cannulae (23 gauge, length $12 \mathrm{~mm}$ ) were implanted bilaterally $1 \mathrm{~mm}$ above the prelimbic region of the medial PFC (mPFC; $A P=$ $+3.0 \mathrm{~mm} ; \mathrm{ML}= \pm 0.5 \mathrm{~mm}$; DV $=-2.3 \mathrm{~mm}$ ), according to the rat brain atlas (Paxinos and Watson, 2007). Two micro screws were inserted in the skull and fixed with dental acrylic. Behavioral experiments started three days after surgery.

\section{Drugs}

CBD (THC-Pharm, Frankfurt, Germany) was dissolved in grape seed oil for intra-PFC microinjections. For microinjections, we used a 33-G needle $1 \mathrm{~mm}$ longer than the guide cannula, aiming at the $-3.3 \mathrm{~mm}$ DV coordinate of the prelimbic region. The solutions were prepared immediately before the tests and were protected from the light during the experimental session. The dose of CBD was chosen based on previous reports and on pilot studies in our laboratory showing its effect on fear memory (Bitencourt et al., 2008; Campos and Guimarães, 2008; Lemos et al., 2010; Do Monte et al., 2013).

\section{Behavioral procedures}

All behavioral procedures were performed in a conditioning chamber made of a metal floor with 18 bars $(2 \mathrm{~mm}$ diameter; spaced $1 \mathrm{~cm})$ and acrylic walls $(23 \times 23 \times 24 \mathrm{~cm})$. The floor was connected to a software-controlled scrambler shock generator (Insight, Brazil). The apparatus was cleaned with $30 \%$ ethanol and water between each trial. For contextual fear conditioning, rats were placed in the conditioning chamber for habituation followed by the conditioning session. Habituation consisted of a $4 \mathrm{~min}$ pre-exposure to the conditioning chamber. During conditioning, animals were exposed to five electrical footshocks $(1.0 \mathrm{~mA} / 2 \mathrm{~s}), 75 \mathrm{~s}$ apart. Immediately $(0 \mathrm{~h})$ or $5 \mathrm{~h}$ after training, animals received bilateral intra-PFC microinjections of CBD $(0.2 \mu \mathrm{l} /$ hemisphere; [CBD] $=2 \mu \mathrm{g} / \mu \mathrm{l} ; \quad$ flow $=0.1 \mu \mathrm{l} / / \mathrm{min})$ or $\mathrm{VEH} \quad(0.2 \mu \mathrm{l} /$ hemisphere; grape seed oil). Two retrieval sessions were performed: one at $24 \mathrm{~h}$ and another 5 days after conditioning. They consisted of re-exposing the animals to the same context where they were shocked for $8 \mathrm{~min}$, but with no acoustic stimulus or footshock. Freezing 
behavior was used as an index of fear memory during subsequent non-reinforced re-exposure to the context. It was defined as a behavioral arrest with immobility of the animal in a stereotyped position, except for movements necessary for breathing (Fanselow, 1976). Freezing behavior was recorded with a video camera and further quantified in blocks of $15 \mathrm{~s}$ by an experimenter blinded to the experimental condition.

\section{High-performance liquid chromatography with electrochemical detection (HPLC-ED)}

Dopamine, 3,4-dihydroxyphenylacetic acid (DOPAC), serotonin (5-HT), and 5-hydroxyindole-3-acetic acid (5HIAA) concentrations were measured in tissue samples of PFC by HPLC-ED as previously described (Lopes Aguiar et al., 2008). After all behavioral procedures, two groups of animals (VEH and CBD group) were prepared for monoamine quantification. Briefly, rats were killed by decapitation under $\mathrm{CO}_{2}$ anesthesia and the brains were removed, immediately frozen on dry ice and stored at $-70^{\circ} \mathrm{C}$. Using a cryostat at $-10^{\circ} \mathrm{C}$, microdissections of the mPFC were performed bilaterally by the punch method accordingly to the rat brain atlas (Palkovits, 1973; Paxinos and Watson, 2007). The microdissections were homogenized in a solution of $0.2 \mathrm{M}$ perchloric acid containing $8 \mathrm{ng} / \mathrm{mL}$ of 3,4-dihydroxybenzylamine, as internal standard. The homogenates were centrifuged for $20 \mathrm{~min}$ at $12,000 \mathrm{~g}$. The supernatant was taken for monoamine analysis and the pellets were used for determination of protein content (Bradford, 1976). Separation was performed on a $250 \times 4 \mathrm{~mm} \mathrm{C18}$ column (Purospher Star, $5 \mu \mathrm{m}$, Merck), preceded by a $4 \times 4 \mathrm{~mm}$ C18 guard column. The mobile phase consisted of $100 \mathrm{mM}$ sodium dihydrogen phosphate ( $\mathrm{pH} 3.5), 10 \mathrm{mM}$ sodium chloride, $0.1 \mathrm{mM}$ EDTA, $0.20 \mathrm{mM}$ sodium 1-octanesulfonic acid, and $15 \%$ methanol. The pump flow rate was $0.6 \mathrm{~mL} / \mathrm{min}$ and the electrochemical potential was set to $600 \mathrm{mV}$ versus in situ $\mathrm{Ag} / \mathrm{AgCl}$ reference electrode. Chromatography data were plotted with Class-VP software (Shimadzu, Kyoto, Japan). Quantification was performed using the internal standard method based on the area under the peak. All samples from the experiment were measured in the same assay. The intra-assay coefficient of variation was less than $5 \%$ for all measured compounds. The neurotransmitter levels (DA and $5-\mathrm{HT}$ ) were considered to reflect neurotransmitter stocks in synaptic vesicles. DOPAC and 5-HIAA levels reflected the release of dopamine and 5-HT, respectively DOPAC/dopamine and 5$\mathrm{HIAA} / 5-\mathrm{HT}$ ratios were taken as an index of neurotransmitter turnover.

\section{Immunohistochemistry}

To investigate the effects of CBD on neuronal activity in limbic-cortical sites, we evaluated the expression of the immediate-early genes c-fos and zif-268. A separate group of animals subjected to the same behavioral procedures as described were anesthetized with urethane $(1.5 \mathrm{~g} / \mathrm{kg}$ ip $0.15 \mathrm{M} \mathrm{NaCl})$ two hours after microinjection intra-PFC to perfusion. Transcardial perfusion was carried out with $200 \mathrm{~mL}$ phosphate- buffered saline (PBS) at $25^{\circ} \mathrm{C}$, followed by $400 \mathrm{~mL}$ of the fixative solution consisting in paraformaldehyde (PFA) $4 \%$ in phosphate buffer (PB) with $\mathrm{pH} 7.4$ at $4{ }^{\circ} \mathrm{C}$. Brains were removed from the skull, post-fixed in PFA for $4 \mathrm{~h} / 4{ }^{\circ} \mathrm{C}$ and immersed in $70 \%$ ethanol for one day, followed by paraffin embedding.

Immunohistochemistry was performed in $8-\mu \mathrm{m}$-thick coronal brain sections, following published protocol (Peixoto-Santos et al., 2012). In order to avoid cannula lesion and secondary tissue damage, we only used sections collected posterior to the cannula track with no signs of scars and gliosis. The sections were submitted to endogenous peroxidase block, antigenic microwave retrieval with citrate buffer $(10 \mathrm{mM}, \mathrm{pH} 6.0)$, and overnight incubation with the primary polyclonal rabbit anti-c-fos (dilution 1:50 in skim milk blocking buffer, cod. sc-52, Santa Cruz Biotechnology), and anti-zif-268 (dilution 1:100, cod sc-189, Santa Cruz Biotechnology). Primary antibody visualization was performed using avidinbiotin-peroxidase complex (Vectastain Elite ABC kit, cod PK6100, Vector) and 3,3'-diaminobenzidine tetrahydrochloride as cromogen (DAB, cod 34001, Pierce Biotechnology, Waltham, Massachusetts, USA).

Micrographs from the regions of interest, delineated according to the Paxinos Atlas (Paxinos and Watson, 2007), were collected with an AxioCamMR5 attached to Axiolmager M1 microscope. All images were obtained with $200 \times$ magnification under constant illumination ( $3 \mathrm{~V}, 60 \mathrm{~ms}$ exposure). The semi-quantitative analysis was performed by threshold tool with ImageJ 1.48 software (National Institutes of Health, USA), following published protocols (Kandratavicius et al., 2013; Wolf et al., 2016). Regions of interest comprised the prelimbic cortex (PL), basolateral nucleus of the amygdala (BLA), mediodorsal thalamic nucleus (MD), paraventricular thalamic nucleus (PVN), reuniens thalamic nucleus $(R e)$, perirhinal cortex (PRh), entorhinal cortex (Ent), ectorhinal cortex (Ect), granular cell layer of hippocampus (DG), and pyramidal layer of hippocampus subfields (CA4, CA3, CA2, and CA1). Results are shown as a percentage of immunopositive area in total area evaluated.

\section{Cannulae placement histology}

All animals, except those subjected to the brain microdissection protocol, were subjected to histological examination. After the behavioral tests, all animals were decapitated under $\mathrm{CO}_{2}$ anesthesia and were transcardiacally perfused with $100 \mathrm{~mL}$ of $\mathrm{NaCl} 0.15 \mathrm{M}$ followed by $250 \mathrm{~mL}$ of $4 \%$ formaldehyde in $0.1 \mathrm{M}$ PBS, $\mathrm{pH}$ 7.4. Brains were removed, post-fixed in the formaldehyde solution for $14 \mathrm{~h}$ at $4{ }^{\circ} \mathrm{C}$ and cryoprotected for $48 \mathrm{~h}$ in $20 \%$ sucrose solution. After freezing in dry ice-chilled isopentane, brains were cut along the coronal plane in $30 \mu \mathrm{m}$ slices, mounted on gelatinized slides and processed for cresyl violet staining. Injection sites were determined after analysis of the slides with a bright field microscope (BX-60 Olympus, Center Vally, PA, USA). Only animals showing accurate cannula placement were included in the statistical analysis. 
Behavioral data were analyzed by a two-way analysis of variance (ANOVA) for repeated measures (Two-way ANOVA RM). Post-hoc comparisons were performed using the Bonferroni test. Neurotransmitter and metabolite levels were evaluated by Student's $t$-test. Non-Gaussian distribution variables were tested using Wilcoxon Rank-Sum Test (Rank-Sum Test). All results are expressed as mean \pm SEM (standard error of mean) and statistical significance defined as $p<0.05$.

\section{RESULTS}

\section{mPFC CBD injection $5 \mathrm{~h}$ after conditioning affects emotional memory formation}

To evaluate whether CBD interferes with PFC-dependent processes important for emotional memory formation in a time-dependent manner, we bilaterally infused CBD intraPFC immediately $(0 \mathrm{~h})$ and $5 \mathrm{~h}$ after training (Fig. 1A, B). As shown in Fig. $1 \mathrm{C}$, the freezing rate decreased over time independently of the group $[-30.4 \%$ in $24 \mathrm{~h}$ test, $-40.6 \%$ in $5 \mathrm{~d}$ test; $F(2,36)=25.024 ; p<0.001$; Twoway ANOVA-RM]. Besides, CBD injection immediately $(0 \mathrm{~h})$ after conditioning did not influence consolidation of contextual fear memory measured by freezing rates at ANOVA-RM). As mentioned in the Introduction section,

\section{Statistical analysis} $24 \mathrm{~h}$ and $5 \mathrm{~d}$ tests $[F(1,36)=0.278 ; p>0.05$; Two-way

the PFC seems to be more engaged in contextual fear memory consolidation during a window of opportunity from 3 to $6 \mathrm{~h}$ after conditioning (Izquierdo et al., 2007). We observed that animals submitted to CBD infusion into the PFC $5 \mathrm{~h}$ after training displayed lower rates of freezing behavior in the 5-d test when compared to the control group $(-12 \% ; \quad F(2,66)=3.328 ; p<0.05$; treatmenttime interaction; $p<0.001$; Bonferroni test; Fig. 1D).

\section{mPFC CBD injection $5 \mathrm{~h}$ after conditioning decreases cortical dopamine release}

Here, we measured DA and serotonin release following memory retrieval 5 days after training. We analyzed the monoamines and their metabolites in PFC samples using HPLC-ED fractionation (Fig. 2A). We observed that CBD significantly decreased the DOPAC/DA ratio when compared to the control group $(-38 \% ; p<0.05 ; t$ test; Fig. 2B). 5-HT and 5-HIAA levels were not affected by CBD treatment ( $p>0.05$; Student's $t$-test; Fig. $2 \mathrm{C}$ ).

\section{mPFC CBD $5 \mathrm{~h}$ after conditioning reduces genes expression in cortico-limbic circuits}

To test whether bilateral CBD injection into the PFC was able to disrupt activity-related gene expression in extracortical regions, we examined c-fos and zif-268 in areas relevant for memory consolidation. Perfusion and brain processing were performed two hours after intra-PFC drug
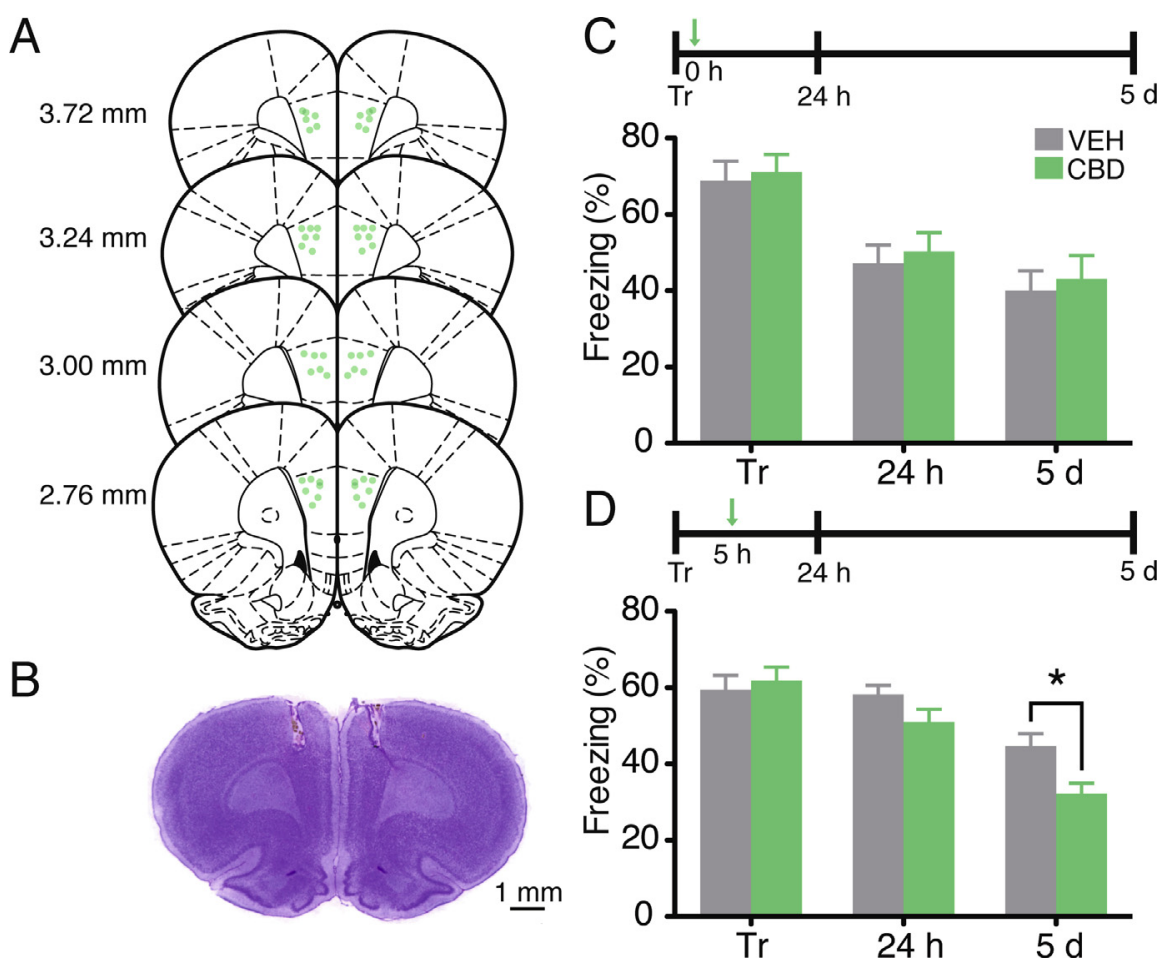

Fig. 1. Intra-PFC CBD infusion $5 \mathrm{~h}$ after training impairs consolidation of remote contextual aversive memory. (A) Diagrams illustrating representative injection sites. Animals were included in the analyses contingent upon correct cannula placement above the PL. (B) Typical tracts from bilateral cannula implantation, as shown by a representative cresyl-stained coronal section. (C) $\mathrm{CBD}$ infusion $0 \mathrm{~h}$ after conditioning does not change freezing on $24 \mathrm{~h}$ and 5 - $\mathrm{d}$ retrieval tests $(p>0.05$; VEH $n=10, \mathrm{CBD} n=10)$. (D) CBD infusion $5 \mathrm{~h}$ after conditioning reduces freezing on $5 \mathrm{~d}$ retrieval test $(-12 \%, p<0.01$; VEC $n=16$, CBD $n=19)$. All data are presented as mean \pm SEM. ${ }^{*} p<0.01$ Two-way ANOVA RM, post hoc Bonferroni. Tr, conditioning. administration (Fig. 3A). Immunohistochemistry analyses showed that CBD decreased c-fosimmunoreactivity in the PL of the mPFC, midline thalamic structures and hippocampal regions ( $p<0.05$; $t$ test; Fig. 3B). Consistently, CBD also decreased zif-268immunoreactivity in the midline thalamus and hippocampal structures $(p<0.05$; Student's $t$ test; Fig. 3C).

\section{DISCUSSION} CBD administration disrupts contextual fear memory consolidation when infused $5 \mathrm{~h}$ after training. This effect is associated with (1) decreased dopaminergic release in the PFC at retrieval 5 days after training and (2) decreased c-fos and zif-268 protein expression in the prelimbic cortex, and a subset of PFC projection targets, such as the midline thalamus and hippocampus.

Besides its role in working memory, the PFC is important for aversive learning and emotional memory expression (Rozeske et al.,
Our findings indicate that intra-PFC 
A
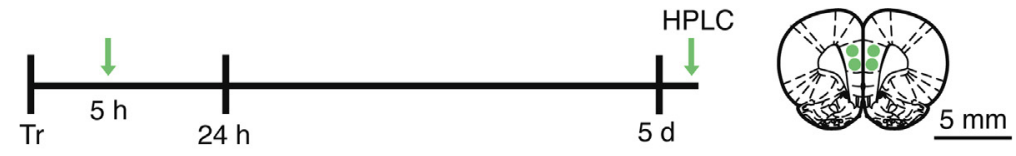

$\mathrm{B}$

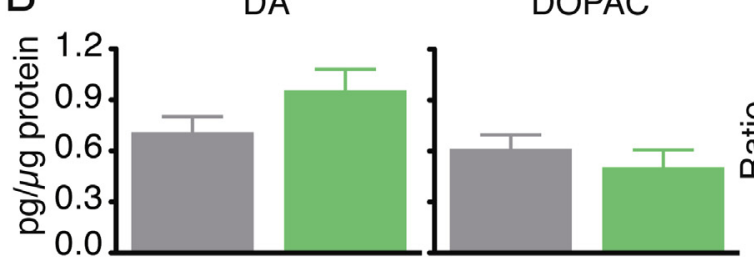

$\mathrm{C}$
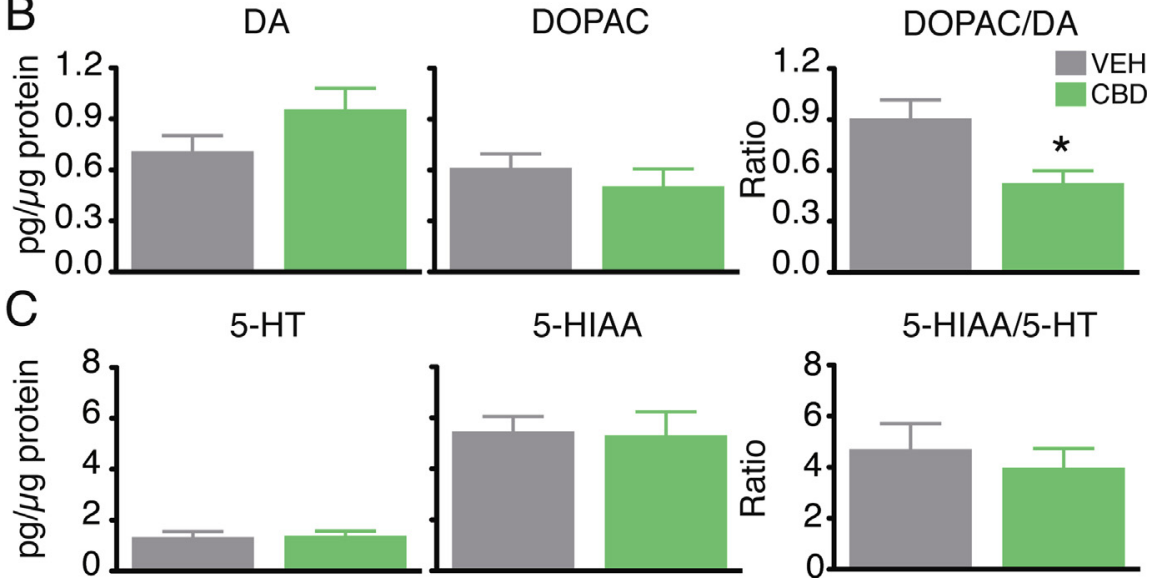

Fig. 2. Intra-PFC CBD infusion $5 \mathrm{~h}$ after training reduces dopamine release in $\mathrm{mPFC}$. (A) Experimental paradigm for quantification of monoamines. (B) Schematic representation of the mPFC sites from which the samples were collected through micro-dissection. (C) CBD infusion $5 \mathrm{~h}$ after conditioning decreases DOPAC/DA ratio in the mPFC $(-42 \% ; p<0.05$; VEH $n=5$, CBD $n=6$ ). (D) CBD infusion $5 \mathrm{~h}$ after training does not change the level of 5-HT and 5-HIAA, or the 5 -HIAA/5-HT ratio $(p>0.05$; VEH $n=5$, CBD $n=5)$. Data are shown as mean \pm SEM. ${ }^{*} p<0.05$ compared with control, $t$-test. Tr, conditioning.

2015; Giustino and Maren, 2015). Inactivation of the prelimbic and infralimbic subfields reduces fear expression to context and memory extinction, respectively (Corcoran and Quirk, 2007; Sierra-Mercado et al., 2011). In fact, it has been postulated that memory consolidation involves a time-dependent reorganization of activity in the PFC and associated limbic structures (hippocampus, amygdala and entorhinal cortex) (Preston and Eichenbaum, 2013; Izquierdo et al., 2016). In support to this, intraPFC infusion of dopamine D1, amino-hydroxymethyl-iso xazole propionate (AMPA) and glutamate N-methyl-Daspartate (NMDA) receptor antagonists or infusion of $\gamma$ amino-butyrate type $A\left(G A B A_{A}\right)$ agonist were shown to interfere with aversive memory consolidation at distinct time windows. This effect was significant when applied at different time-points between 1.5 and $12 \mathrm{~h}$ after fear conditioning (Souza et al., 2000; Izquierdo et al., 2007; Gonzalez et al., 2014). In particular, blockade of D1 receptors in the medial PFC $6 \mathrm{~h}$ after training disrupts the long-term retrieval of a step-down inhibitory avoidance memory (Gonzalez et al., 2014).

Moreover, contextual fear memory consolidation can elicit early transcriptional, structural, and functional remodeling of PFC cells few hours after conditioning (Vetere et al., 2011; Bero et al., 2014). These observations are consistent with the demonstration that PFC neurons are reactivated during encoding of associative memories (Lesburguères et al., 2011). This process is thought to be driven by the hippocampus, leading to a gradual consolidation of contextual fear memories (Laroche and Davis, 2000; Restivo et al., 2009). Our findings show that intra-PFC CBD infusion at a particular time window after training $(5 \mathrm{~h})$ disrupts the formation of longterm emotional memory 5 days later. In accordance with its amnesic effects, it has been demonstrated that CBD infusions before training impairs long-term aversive memory acquisition (Resstel et al., 2006; Lemos et al., 2010); facilitation of aversive memory extinction before retrieval test (Bitencourt et al., 2008); and disruption of aversive memory reconsolidation immediately after retrieval test (Stern et al., 2012). Recently, it has been reported that $C B D$ can modulate DA release and decrease the population activity of mesolimbic neurons (Ren et al., 2009; Murillo-Rodríguez et al., 2011, 2014). PFC dopaminergic neurotransmission is also essential for long-term storage of contextual fear memories (Espejo, 2003), which is supported by studies showing that reduced levels of DA release during contextual fear memory acquisition are associated with reduced freezing behavior (Pezze and Feldon, 2004; Ikegami et al., 2014). In response to fear expression, PFC neurons display periods of burst firing (Burgos-robles et al., 2007) that are associated with increased dopaminergic neuronal activity (Lodge, 2011). In addition, dopamine receptor activation in the hippocampus and PFC plays an important role in the long-term consolidation of fear memories (Izquierdo et al., 2006, 2007; Rossato et al., 2009). In fact, intra-CA1 infusion of D1 receptor antagonists $3 \mathrm{~h}$ or $6 \mathrm{~h}$ post-training has been shown to decrease step-down inhibitory avoidance latency (i.e. aversive memory expression) during memory retrieval (Bevilaqua et al., 1997). Similarly, intra-PFC infusions of D1 receptor antagonists $3 \mathrm{~h}$ after conditioning disrupt the consolidation of fear memory in the same task (Izquierdo et al., 2007). Consistent with these studies, our results indicate that intra-PFC infusions of CBD impaired memory consolidation and the expression of aversive memory at a retrieval session 5 days after training. Interestingly, such poor performance correlated with a decrease in dopamine release in the PFC. Although we did not measure dopamine levels following CBD administration, we hypothesize that the acute inhibitory action of CBD following training may have produced long-lasting effects on the PFC local circuitry with implications to memory performance and dopamine release, through its projections to the ventral tegmental area. In fact, the reduced neuronal activation of the prelimbic region during retrieval could be the result of a diminished feedback from brainstem dopaminergic neurons due to PFC inhibition (Karreman and Moghaddam, 1996).

Although it is well documented that CBD facilitates fear memory extinction (Bitencourt et al., 2008; Do Monte et al., 2013), its effects on a network scale, measured by activity-dependent gene expression in multiple limbic structures during aversive memory consolidation, are still unknown (Izzo et al., 2009). Here, we observed that intra-PFC CBD infusions produced similar patterns 

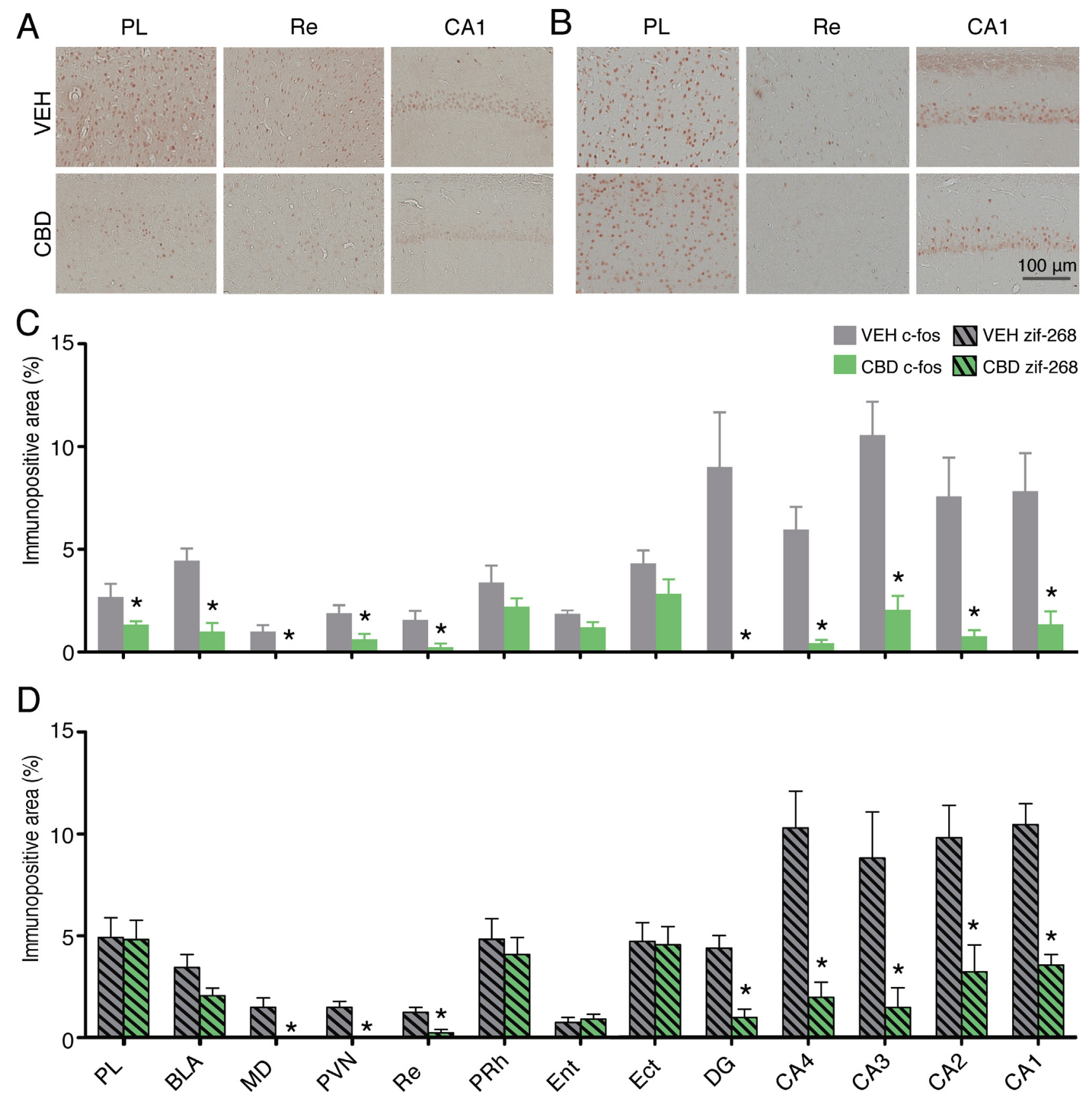

Fig. 3. Intra-PFC CBD infusion $5 \mathrm{~h}$ after conditioning reduces c-fos and zif-268 expression in limbic structures. (A) Experimental paradigm for immunohistochemical quantification of c-fos and zif-268. (B) CBD infusion $5 \mathrm{~h}$ after conditioning reduces the immunopositive area for $\mathrm{C}$-fos on $\mathrm{PL}$ $(-50 \%)$, BLA $(-78 \%)$; MD $(-100 \%)$, PVN $(-70 \%)$, Re $(-83 \%)$, DG $(-100 \%)$, CA4 $(-93 \%)$, CA3 $(-81 \%)$, CA2 $(-90 \%)$ and CA1 $(-83 \%)($ VEH $n=7-9$, CBD $n=7-9)$. (C) CBD $5 \mathrm{~h}$ after conditioning reduces immunopositive area for zif-268 on MD $(-100 \%), \mathrm{PVN}(-100 \%), \operatorname{Re}(-80 \%), \mathrm{DG}$ $(-77 \%)$, CA4 $(-81 \%)$, CA3 $(-83 \%)$, CA2 $(-67 \%)$ and CA1 $(-66 \%)$ (VEH $n=4-7$, CBD $n=4-8)$. Data are shown as mean \pm SEM. ${ }^{*} p<0.05$ compared to control, Student's $t$-test. Tr, conditioning; PL, prelimbic cortex; MD, mediodorsal thalamic nucleus; PVN, paraventricular thalamic nucleus; Re, reuniens thalamic nucleus; PRh, perirhinal cortex; Ent, entorhinal cortex; Ect, ectorhinal cortex and DG, granular cell layer of hippocampus.

of c-fos and zif-268 gene expression in mPFC targets such as the hippocampus, midline thalamus, amygdala and rhinal cortices. Although c-fos and zif-268 represent activity-dependent immediately early genes with different activation sensitivities, their expression levels were similarly reduced in all limbic areas analyzed with the exception of rhinal (entorhinal, perirhinal and ectorhinal) cortices. In the BLA and PL, however, zif-268 levels did not change after CBD administration, possibly due to the low signal-to-noise ratio for zif-268 as a result of its high basal levels in the rodent brain. The fact that activity-dependent gene expression in the rhinal cortices was not altered after intra-PFC CBD infusion argues against a generalized inhibitory effect of CBD on PFC 
targets. Selective decrease of neuronal activity induced by CBD is supported by previous in vitro and in vivo studies. In vitro application of CBD differentially reduces burst amplitude and frequency of local field potentials in slices of epileptic hippocampus, subfields CA1, CA3 and DG (Jones et al., 2010). Furthermore, systemic injection of CBD in rodents promotes restricted patterns of brain activation. It increases $c$-fos expression in the nucleus accumbens, but not in the striatum, as well as decreases c-fos expression in the mPFC (Guimarães et al., 2004; Lemos et al., 2010). An important experimental aspect of our study is that we used bilateral CBD infusions into the $\mathrm{mPFC}$ in a very small volume $(0.2 \mu \mathrm{L} /$ hemisphere; $2.0 \mu \mathrm{g} / \mu \mathrm{L}$ ). So, we can confidently assert that its effects were mediated by its direct action on the PFC activity and not due to widespread brain diffusion of the drug.

Considering that the activity-dependent expression of zif-268 is associated with the consolidation of long-lasting memories (Frankland et al., 2004; Goshen et al., 2011), it is interesting to notice that reduced c-fos and zif-268 expression in response to intra-PFC CBD injection were not restricted to the PFC or generalized, but were found in some of the PFC target regions. This implicates the inhibition of neuronal activity in some cortical targets in the impairment of long-term aversive memory. Neuronal tracing studies have shown that the PFC reciprocally projects to the BLA (Hübner et al., 2014) and midline thalamus (Vertes and Hoover, 2008; Varela et al., 2014; Rozeske et al., 2015). Besides, the PFC can indirectly modulate hippocampus activity through its efferences to the nucleus reuniens of the midline thalamus, which directly projects to CA1 (Varela et al., 2014). CA1, in turn, sends excitatory monosynaptic projections back to the PFC (Jay and Witter, 1991; Laroche and Davis, 2000; Gabbott et al., 2002), closing the thalamus-hippocampusprefrontal cortex loop (Cenquizca and Swanson, 2007). Interestingly, direct inactivation of nucleus reuniens is sufficient to disrupt the expression of contextual fear memory (Xu and Südhof, 2013) and, lesions in this region reduce dendritic branching in the PFC and hippocampus (Torres-Garcia et al., 2012). Therefore, we postulate that CBD modulation of PFC activity $5 \mathrm{~h}$ post-training interferes with contextual fear memory formation by reducing its influence on thalamo-limbic circuits.

\section{CONCLUSIONS}

In summary, the present study shows that CBD into the PFC interferes on memory consolidation in a selective post-training time window. This effect is associated with reduced dopaminergic modulation in PFC and reduced immediately-gene expression in thalamic-limbic circuits.

\section{CONFLICTS OF INTEREST}

J.E.C.H., A.W.Z., and J.A.C are co-inventors (Mechoulam R., Crippa J.A., Guimaraes F.S., Zuardi, A.W, Hallack J. E.C., Breuer A.) of the patent "Fluorinated CBD compounds, compositions and uses thereof. Pub. No.: WO/2014/108899. International Application No.: PCT/ IL2014/050023"; Def. US No. Reg. 62193296; 29/07/2015; INPI em 19/08/2015 (BR1120150164927).
University of São Paulo licensed it to Phytecs Pharm (Resolução USP No. 15.1.130002.1.1). University of São Paulo has an agreement with Prati-Donaduzzi (Toledo, Brazil): "Desenvolvimento de um produto farmacêutico contendo canabidiol sintético e comprovação de sua segurança e eficácia terapêutica na epilepsia, esquizofrenia, doença de Parkinson e transtornos de ansiedade". J.A.C. and J.E.C.H. received a travel support from BSPG-Pharm. All the other authors declare that the research was conducted in the absence of any commercial or financial relationships that could be construed as a potential conflict of interest.

\section{AUTHOR CONTRIBUTIONS}

Designed the experiments: MTR, CLA, RNRP.

Performed the experiments: MTR, RNR.

Contributed with data collection: RADVS, LK, JEPS, RES.

Analyzed the data: MTR, CLA, RNR, LSBJ, LK, JEPS, RNRP.

Edited the figures: MTR, CLA.

Wrote the paper: MTR, CLA, RNR, RADVS, LSBJ, LK, JEPS, JAC, JECH, AWZ, RES, JAF, JPL, RNRP.

Formatted/submitted the paper: RNRP. Institutional support: JAC, JECH, AWZ, JAF, JPL. All authors have approved the final manuscript.

Acknowledgments-We would like to thank Renata Caldo Scandiuzzi, Ruither de Oliveira Gomes Carolino and Antônio Renato Meirelles e Silva for their excellent technical support. We also thank THC-Pharm (Frankfurt, Germany), STI-Pharm (Brentwood, UK) and BSPG-Pharm (Sandwich, UK) for kindly supply our studies of CBD at no cost. This study was financed by the Brazilian National Council for Scientific and Technological Development (CNPq) (grants: 119628/2009-0, 476250/2013-7, 466995/20148, 466805/2014-4, 423977/2016-4) and São Paulo Research Foundation (FAPESP) (grant: 2012/23918-0, 2014/09772-9, 2015/20840-9, 2016/17882-4).

\section{REFERENCES}

Aceti M, Vetere G, Novembre G, Restivo L, Ammassari-teule M (2015) Neurobiology of learning and memory progression of activity and structural changes in the anterior cingulate cortex during remote memory formation. Neurobiol Learn Mem 123:67-71.

Bero AW, Meng J, Cho S, Shen AH, Canter RG, Ericsson M, Tsai L (2014) Early remodeling of the neocortex upon episodic memory encoding. PNAS 111(32):11852-11857.

Bevilaqua L, Ardenghi P, Schorder N, Bromberg E, Schmitz PK, Schaeffer E, Quevedo J, Bianchin M, Walz R, Medina JH, Izquierdo I (1997) Drugs acting upon the cyclic adenosine monophosphate/protein kinase A signalling pathway modulate memory consolidation when given late after training into rat hippocampus but not amygdala. Behav Pharmacol 8(4):331-338.

Bitencourt RM, Pamplona Fa, Takahashi RN (2008) Facilitation of contextual fear memory extinction and anti-anxiogenic effects of AM404 and cannabidiol in conditioned rats. Eur Neuropsychopharmacol 18:849-859.

Bradford MM (1976) A rapid and sensitive method for the quantitation of microgram quantities of protein utilizing the principle of proteindye binding. Anal Biochem 72:248-254.

Burgos-robles A, Vidal-gonzalez I, Santini E, Quirk GJ (2007) Consolidation of fear extinction requires NMDA receptor- 
dependent bursting in the ventromedial prefrontal cortex. Neuron 53(15):871-880.

Campos AC, Guimarães FS (2008) Involvement of 5HT1A receptors in the anxiolytic-like effects of cannabidiol injected into the dorsolateral periaqueductal gray of rats. Psychopharmacology (Berl) 199:223-230.

Campos AC, Moreira FA, Gomes FV, Del Bel EA, Guimaraes FS (2012) Multiple mechanisms involved in the large-spectrum therapeutic potential of cannabidiol in psychiatric disorders. Philos Trans R Soc B Biol Sci 367:3364-3378.

Cenquizca LA, Swanson LW (2007) Spatial organization of direct hippocampal field CA1 axonal projections to the rest of the cerebral cortex. Brain Res Rev 56:1-26.

Corcoran KA, Quirk GJ (2007) Activity in prelimbic cortex is necessary for the expression of learned, but not innate, fears. J Neurosci 27(4):840-844.

Devinsky O, Cilio MR, Cross H, Fernandez-ruiz J, Hill C, Katz R, Consultant I, Di Marzo V, Notcutt WG, Martinez-orgado J, Robson PJ, Rohrback BG, Thiele E, Whalley B, Friedman D (2014) Cannabidiol: pharmacology and potential therapeutic role in epilepsy and other neuropsychiatric disorders. Epilepsia 55 (6):791-802.

Do Monte FH, Souza RR, Bitencourt RM, Kroon JA, Takahashi RN (2013) Infusion of cannabidiol into infralimbic cortex facilitates fear extinction via CB1 receptors. Behav Brain Res 250:23-27.

Dudai Y, Karni A, Born J (2015) Perspective the consolidation and transformation of memory. Neuron 88:20-32.

Espejo EF (2003) Prefrontocortical dopamine loss in rats delays longterm extinction of contextual conditioned fear, and reduces social interaction without affecting short-term social interaction memory. Neuropharmacology 28:490-498.

Fanselow MS (1976) Conditional and unconditional components of post-shock freezing. Pavlov J Biol Sci 15(4):177-182.

Fogaça MV, Reis FMCV, Campos AC (2014) Effects of intraprelimbic prefrontal cortex injection of cannabidiol on anxietylike behavior: involvement of $5 \mathrm{HT} 1 \mathrm{~A}$ receptors and previous stressful experience. Eur Neuropsychopharmacol 24:410-419.

Frankland PWPWPW, Bontempi B, Talton LE, Kaczmarek L, Silva AAJ (2004) The involvement of the anterior cingulate cortex in remote contextual fear memory. Science 304:881-883.

Gabbott P, Headlam A, Busby S (2002) Morphological evidence that CA1 hippocampal afferents monosynaptically innervate PVcontaining neurons and NADPH-diaphorase reactive cells in the medial prefrontal cortex (Areas 25/32) of the rat. Brain Res 946:314-322.

Giustino T, Maren S (2015) The role of the medial prefrontal cortex in the conditioning and extinction of fear. Front Behav Neurosci 9:298.

Gonzalez MC, Cecilia P, Tomaiuolo M, Katche C, Weisstaub N (2014) Medial prefrontal cortex dopamine controls the persistent storage of aversive memories. Front Behav Neurosci 8:1-7.

Goshen I, Brodsky M, Prakash R, Wallace J, Gradinaru V, Ramakrishnan C, Deisseroth K (2011) Dynamics of retrieval strategies for remote memories. Cell 147:678-689.

Guimarães VM, Zuardi AW, Del Bel EA, Guimarães FS (2004) Cannabidiol increases Fos expression in the nucleus accumbens but not in the dorsal striatum. Life Sci. 75(5):633-638.

Hübner C, Bosch D, Gall A, Lüthi A, Ehrlich I (2014) Ex vivo dissection of optogenetically activated mPFC and hippocampal inputs to neurons in the basolateral amygdala: implications for fear and emotional memory. Front Behav Neurosci 8:64.

Ikegami M, Uemura T, Kishioka A, Sakimura K, Mishina M (2014) Striatal dopamine D1 receptor is essential for contextual fear conditioning. Sci Rep 4(3976):1-10.

Izquierdo I, Bevilaqua LRM, Rossato JI, Bonini JS, Medina JH, Cammarota M (2006) Different molecular cascades in different sites of the brain control memory consolidation. Trends Neurosci 29:496-505.

Izquierdo LA, Barros DM, Costa J, Furini C, Zinn C, Cammarota M, Bevilaqua LR, Izquierdo I (2007) A link between role of two prefrontal areas in immediate memory and in long-term memory consolidation. Neurobiol Learn Mem 88:160-166.

Izquierdo I, Furini CRG, Myskiw J (2016) Fear memory. Physiol. Rev. 96:695-750.

Izzo AA, Borrelli F, Capasso R, Di Marzo V, Mechoulam R (2009) Non-psychotropic plant cannabinoids: new therapeutic opportunities from an ancient herb. Trends Pharmacol Sci 30 (10):515-527.

Jay TM, Witter MP (1991) Distribution of hippocampal CA1 and subicular efferents in the prefrontal cortex of the rat studied by means of anterograde transport of Phaseolus vulgarisleucoagglutinin. J Comp Neurol 313:574-586.

Jones NA, Hill AJ, Smith I, Bevan SA, Williams CM, Whalley BJ, Stephens GJ (2010) Cannabidiol Displays Antiepileptiform and Antiseizure Properties In Vitro and In Vivo. J Pharmacol Exp Ther 332(2):569-577.

Kandratavicius L, Rosa-Neto P, Monteiro MR, Guiot MC, Assirati Jr JA, Carlotti Jr CG, Kobayashi E, Leite JP (2013) Distinct increased metabotropic glutamate receptor type 5 (mGluR5) in temporal lobe epilepsy with and without hippocampal sclerosis. Hippocampus 23:1212-1230.

Karreman M, Moghaddam B (1996) The prefrontal cortex regulares the basal release of dopamine in the limbic striatum: an effect mediated by ventral tegmental area. J Neurochem 66 (2):589-598.

Laroche S, Davis S (2000) Plasticity at hippocampal to prefrontal cortex synapses: dual roles in working memory and consolidation. Hippocampus 10:438-446.

Lemos JI, Resstel LB, Guimarães FS (2010) Involvement of the prelimbic prefrontal cortex on cannabidiol-induced attenuation of contextual conditioned fear in rats. Behav Brain Res 207:105-111.

Lesburguères E, Gobbo OL, Alaux-Cantin S, Hambucken A, Trifilieff P, Bontempi B (2011) Early tagging of cortical networks is required for the formation of enduring associative memory. Science 331:924-928.

Lodge DJ (2011) The medial prefrontal and orbitofrontal cortices differentially regulate dopamine system function. Neuropsychopharmacology 36:1227-1236.

Lopes Aguiar C, Romcy-Pereira RN, Szawka RE, Galvis-Alonso OY, Anselmo-Franci JA, Pereira Leite J (2008) Muscarinic acetylcholine neurotransmission enhances the late-phase of long-term potentiation in the hippocampal-prefrontal cortex pathway of rats in vivo: a possible involvement of monoaminergic systems. Neuroscience 153(4):1309-1319.

Mechoulam R, Hanuš L (2002) Cannabidiol: An overview of some chemical and pharmacological aspects. Part I: Chemical aspects. Chem Phys Lipids 121:35-43.

Murillo-Rodríguez E, Palomero-Rivero M, Millán-Aldaco D, Mechoulam R, Drucker-Colín R (2011) Effects on sleep and dopamine levels of microdialysis perfusion of cannabidiol into the lateral hypothalamus of rats. Life Sci 88:504-511.

Murillo-Rodríguez E, Sarro-Ramírez A, Sánchez D, Mijangos-Moreno S, Tejeda-Padrón A, Poot-Aké A, Guzmán K, Pacheco-Pantoja E, Arias-Carrión O (2014) Potential effects of cannabidiol as a wakepromoting agent. Curr Neuropharmacol 12:269-272.

Palkovits M (1973) Isolated removal of hypothalamic or other brain nuclei of the rat. Brain Res 59:449-450.

Parsons RG, Ressler KJ (2013) Implications of memory modulation for post-traumatic stress and fear disorders. Nat Neurosci 16 (2):146-153.

Paxinos G, Watson C (2007) The rat brain in stereotaxic coordinates. Amsterdam: Academic Press/Elsevier.

Peixoto-Santos JE, Galvis-Alonso OY, Velasco TR, Kandratavicius L, Assirati JA, Carlotti CG, Scandiuzzi RC, Serafini LN, Leite JP (2012) Increased metallothionein I/II expression in patients with temporal lobe epilepsy. PLoS One 7:1-11.

Pertwee RG (2008) The diverse CB 1 and CB 2 receptor pharmacology of three plant cannabinoids: D9tetrahydrocannabinol, cannabidiol and D9tetrahydrocannabivarin. Br J Pharmacol 153(2):199-215. 
Pezze MA, Feldon J (2004) Mesolimbic dopaminergic pathways in fear conditioning. Prog Neurobiol 74(5):301-320.

Preston AR, Eichenbaum H (2013) Interplay of hippocampus and prefrontal cortex in memory. CURBIO 23:R764-R773.

Ren Y, Whittard J, Higuera-matas A, Morris CV, Hurd YL (2009) Cannabidiol, a nonpsychotropic component of cannabis, inhibits cue-induced heroin seeking and normalizes discrete mesolimbic neuronal disturbances. J Neurosci 29:14764-14769.

Resstel LBM, Joca SRL, Moreira FA, Corrêa FMA, Guimarães FS (2006) Effects of cannabidiol and diazepam on behavioral and cardiovascular responses induced by contextual conditioned fear in rats. Behav Brain Res 172:294-298.

Restivo L, Vetere G, Bontempi B, Ammassari-teule M (2009) The formation of recent and remote memory is associated with timedependent formation of dendritic spines in the hippocampus and anterior cingulate cortex. J Neurosci 29(25):8206-8214.

Rossato JI, Bevilaqua LRM, Izquierdo I, Medina JH, Cammarota M (2009) Dopamine controls persistence of long-term memory storage. Science 325(5943):1017-1020.

Rozeske RR, Valerio S, Chaudun F, Herry C (2015) Prefrontal neuronal circuits of contextual fear conditioning. Genes Brain Behav 14(1):22-36.

Sandkühler J, Lee J (2013) How to erase memory traces of pain and fear. Trends Neurosci 36:343-352.

Sierra-Mercado D, Padilla-Coreano N, Quirk GJ (2011) Dissociable roles of prelimbic and infralimbic cortices, ventral hippocampus, and basolateral amygdala in the expression and extinction of conditioned fear. Neuropsychopharmacology 36(2):529-538.

Souza TME, Vianna MRM, Rodrigues C, Quevedo J, Moleta BA, Izquierdo I (2000) Involvement of the medial precentral prefrontal cortex in memory consolidation for inhibitory avoidance learning in rats. Pharmacol Biochem Behav 66(3):615-622.
Stern CA, Gazarini L, Takahashi RN, Guimarães FS, Bertoglio LJ (2012) On disruption of fear memory by reconsolidation blockade: evidence from cannabidiol treatment. Neuropsychopharmacology 37:2132-2142.

Tayler KK, Wiltgen BJ (2013) New methods for understanding systems consolidation. Learn Mem 20(10):553-557.

Torres-García ME, Solis O, Patricio A, Rodríguez-Moreno A, Camacho-Abrego I, Limón ID, Flores G (2012) Dendritic morphology changes in neurons from the prefrontal cortex, hippocampus and nucleus accumbens in rats after lesion of the thalamic reticular nucleus. Neuroscience 223:429-438.

Tovote P, Fadok JP, Lüthi A (2015) Neuronal circuits for fear and anxiety. Nat Rev Neurosci 16:317-331.

Varela C, Kumar S, Yang JY, Wilson MA (2014) Anatomical substrates for direct interactions between hippocampus, medial prefrontal cortex, and the thalamic nucleus reuniens. Brain Struct Funct 219:911-929.

Vertes RP, Hoover WB (2008) Projections of the paraventricular and paratenial nuclei of the dorsal midline thalamus in the rat. J Comp Neurol 508:212-237.

Vetere G, Restivo L, Cole CJ, Ross PJ, Ammassari-teule M (2011) Spine growth in the anterior cingulate cortex is necessary for the consolidation of contextual fear memory. Proc Natl Acad Sci U S A 108:2-6.

Wolf DC, Bueno-Júnior LS, Lopes-Aguiar C, Do Val da Silva RA, Kandratavicius L, Leite JP (2016) The frequency of spontaneous seizures in rats correlates with alterations in sensorimotor gating, spatial working memory, and parvalbumin expression throughout limbic regions. Neuroscience 312:86-98.

Xu W, Südhof TC (2013) A neural circuit for memory. Science 339 (6125):1290-1296. 